\title{
AMODIAQUINE, SULFADOXINE-PYRIMETHAMINE, AND COMBINATION THERAPY FOR UNCOMPLICATED FALCIPARUM MALARIA: A RANDOMIZED CONTROLLED TRIAL FROM BURKINA FASO
}

\author{
ISSAKA ZONGO, GRANT DORSEY, NOEL ROUAMBA, CHRISTIAN DOKOMAJILAR, MOISE LANKOANDE, \\ JEAN-BOSCO OUEDRAOGO, AND PHILIP J. ROSENTHAL* \\ Institut de Recherche en Science de la Santé, Bobo-Dioulasso, Burkina Faso; University of California, San Francisco, California
}

\begin{abstract}
Increasing resistance to chloroquine necessitates the evaluation of other antimalarial therapies in Africa. We compared the efficacies of amodiaquine (AQ), sulfadoxine-pyrimethamine (SP), and AQ + SP for the treatment of uncomplicated falciparum malaria in a randomized trial of patients 6 months of age or older in Bobo-Dioulasso, Burkina Faso. Of the 944 patients enrolled, 829 (88\%; 53\% under 5 years of age) were assigned 28-day efficacy outcomes. For all regimens, early treatment failures were uncommon $(<2 \%)$. Considering all treatment failures based on WHO criteria, AQ + SP was most efficacious (failures in $4.2 \%)$, followed by SP $(9.1 \%)$ and AQ $(17.9 \% ; P<0.02$ for all pairwise comparisons). Considering only clinical failures, relative efficacies were similar (failures in $2.1 \%$ with AQ + SP, $6.5 \%$ with SP, and $13.2 \%$ with AQ; $P<0.02$ for all pairwise comparisons). The risk of recrudescence was lower with AQ + SP $(2.1 \%)$ compared with SP $(6.1 \%, P=0.02)$ and AQ $(8.1 \%, P=0.001)$. Risks of new infection were lower with AQ + SP $(2.1 \%)$ and SP $(2.4 \%)$ compared with AQ $(9.1 \%, P<0.001$ for both comparisons). No serious adverse events were seen. AQ + SP appears to offer a highly effective, inexpensive, and available therapy for the treatment of uncomplicated malaria in Burkina Faso.
\end{abstract}

\section{INTRODUCTION}

Malaria is one of the most important health problems in sub-Saharan Africa. The main strategy for malaria control in Africa remains prompt and effective treatment of those who present with symptomatic disease. ${ }^{1}$ This strategy is seriously jeopardized by resistance of Plasmodium falciparum to standard antimalarial drugs, in particular chloroquine (CQ) and sulfadoxine-pyrimethamine (SP). ${ }^{2}$ New treatment approaches are clearly needed, but it is not clear which therapies are most appropriate for different parts of Africa.

A new consensus has emerged, arguing that the best means of confronting and halting the progression of antimalarial drug resistance is to use combination treatment regimens. ${ }^{3}$ This strategy was validated in Thailand, where combining mefloquine with artesunate markedly improved treatment efficacy and may have helped to decrease malaria incidence. ${ }^{4}$ Based on success in Asia, the use of artemisinin-based combination therapy (ACT) to treat malaria in Africa is now advocated as an urgent goal. ${ }^{5}$ However, artemisinins require effective partner drugs for treatment success, and it is unclear which partners are most appropriate for Africa. In addition, artemisinins are much more expensive than older drugs, ${ }^{6}$ are of uncertain safety in pregnant women, ${ }^{7}$ and at present are in short supply. ${ }^{8}$ In this context, it is appropriate to consider other regimens that might improve upon the efficacies of monotherapies, help to delay the spread of drug resistance, and offer less expensive and more readily available options for the treatment of malaria.

In Burkina Faso, the standard therapy for malaria has remained CQ. Antimalarial drug resistance has come to West Africa later than to most malarious parts of the world. However, it now appears that resistance to CQ in Burkina Faso is unacceptably high, ${ }^{9}$ and a change to a more efficacious standard regimen is an urgent priority. As is the case with other countries in Africa, Burkina Faso is faced with the need to

\footnotetext{
* Address correspondence to Philip J. Rosenthal, Box 0811, University of California, San Francisco, CA 94143. E-mail: rosnthl@itsa .ucsf.edu
}

improve antimalarial treatment efficacy within significant budgetary constraints. Therefore, in addition to consideration of ACT regimens, it seems prudent to evaluate less expensive, more readily available treatments. We therefore compared the efficacies of amodiaquine (AQ), SP, and the combination of these two drugs for the treatment of uncomplicated malaria in Bobo-Dioulasso, Burkina Faso.

\section{MATERIALS AND METHODS}

Study design and site. The study took place in BoboDioulasso, a city of approximately 450,000 inhabitants, situated in the western region of Burkina Faso. The climate is characterized by rainy (May-October) and dry (NovemberApril) seasons. Malaria is holoendemic in the region, with transmission peaking during the rainy season. Study subjects were recruited from three government health dispensaries in Bobo-Dioulasso (Colsama, Sarfalao, and Ouezzin-ville). These facilities are each staffed by two or three nurses and include a short-term observation room, a delivery room, and a pharmacy with essential generic drugs. The Center Hospitalier Universitaire Souro Sanon in Bobo-Dioulasso served as the referral hospital for patients requiring inpatient care. The study was approved by the institutional review boards of the University of California, San Francisco, and Center Muraz, Bobo-Dioulasso.

Patients. Patients who presented to one of the study dispensaries with symptoms suggestive of malaria (fever or history of recent fever) were referred to the dispensary laboratory for a screening with Giemsa-stained thick blood smear, and those with a positive blood smear were assessed for entry into the study. Blood was also collected for a thin smear, hemoglobin assessment, and storage on filter paper for future molecular studies. Consecutive patients were screened for the following inclusion criteria: 1) age 6 months or older; 2) fever ( $\geq 37.5^{\circ} \mathrm{C}$ axillary) or fever symptoms in the previous 24 hours, 3) absence of any history of serious side effects to study medications, including allergy to sulfa drugs, 4) no evidence of a concomitant febrile illness in addition to malaria, 5) provision of informed consent and ability to participate in 28-day 
follow-up, 6) no history of treatment with any antimalarial other than CQ in the past 2 weeks, 7) no danger signs or evidence of severe malaria, ${ }^{10} 8$ ) absence of repeated vomiting of study medications on Day 0,9) P. falciparum monoinfection, 10) parasite density $\geq 2,000 / \mu \mathrm{L}$ and $\leq 200,000 / \mu \mathrm{L}$, and 11) hemoglobin $\geq 5.0 \mathrm{~g} / \mathrm{dL}$.

After an initial positive screening smear, thick and thin blood smears (for parasite counts and speciation, respectively) were assessed at a central laboratory. Counts were performed by two microscopists; discrepant readings were resolved by a third microscopist. Patients who satisfied the selection criteria and provided informed consent were enrolled in the study. Patients who did not satisfy the selection criteria and were excluded from study enrollment were referred to the dispensary clinical staff for appropriate care.

Baseline evaluation, randomization, and treatment allocation. Upon enrollment, patients were assigned a study number and underwent history and physical examination. Patients were then referred to the study nurse for treatment group assignment. Patients were randomly assigned to one of the three treatment groups: AQ $(10 \mathrm{mg} / \mathrm{kg}$ on Days 0 and 1 and $5 \mathrm{mg} / \mathrm{kg}$ on Day 2), SP (25 mg/kg of sulfadoxine and 1.25 $\mathrm{mg} / \mathrm{kg}$ pyrimethamine as a single dose on Day 0 ), or $\mathrm{AQ}+\mathrm{SP}$, each dosed as in the monotherapy regimens. Patients in monotherapy arms received placebos to match the alternate therapy with respect to number of pills, but not color or taste. Randomization was done according to a predetermined randomization list. Treatment allocation and administration of medications were performed by a study nurse not involved in the assessment of treatment outcomes; the other members of the team were blinded to the treatment regimen.

Medications were administered according to weight-based guidelines from the WHO for administration of fractions of tablets. All doses of study medications were directly observed in the clinic. After treatment, patients were observed for 30 minutes, and the dose was readministered if vomiting occurred. Those who persistently vomited the first dose of study medications were excluded from the study and referred for treatment with parenteral quinine. Patients received a 3-day supply of acetaminophen $(10 \mathrm{mg} / \mathrm{kg}$ ) for use every 8 hours until the resolution of fever. Those with hemoglobin less than $10 \mathrm{~g} / \mathrm{dL}$ were treated according to Integrated Management of Childhood Illness guidelines with ferrous sulfate and given anthelmintic therapy if they were older than 1 year and had not been treated in the previous 6 months.

Follow-up procedures and classification of treatment outcomes. Patients were asked to return to the clinic for followup on Days 1, 2, 3, 7, 14, 21, 28, and any unscheduled day that they felt sick. Subjects who did not return for a scheduled follow-up appointment were visited at home. Each visit consisted of completion of a standardized history form and physical examination. Blood was obtained by finger prick on Days $2,3,7,14,21,28$, and on any unscheduled visit for thick blood smears and to save on filter paper. Hemoglobin was reevaluated on Day 28 or at the time of clinical treatment failure. All thick smears were assessed for parasite density and presence of gametocytes. A repeat thin smear for speciation was performed on any patient who presented with a clinical treatment failure after Day 3.

Patients were followed for 28 days and their treatment outcomes assessed according to WHO guidelines for areas of intense malaria transmission as adequate clinical and parasi- tological response (ACPR), early treatment failure (ETF), late clinical failure (LCF), and late parasitological failure (LPF). ${ }^{10}$ Secondary outcomes included time to resolution of fever, time to parasite clearance, change in hemoglobin level, presence of gametocytes during follow-up, and the occurrence of adverse events. Patients who were classified as treatment failures (ETF, LCF, or LPF) were treated with quinine $(10 \mathrm{mg} / \mathrm{kg}$ orally three times a day for 7 days). Patients with evidence of severe malaria or danger signs (convulsions, lethargy, unable to drink or breast feed, repeated vomiting, unable to stand/sit due to weakness $)^{10}$ were referred for treatment with parenteral quinine. Patients were excluded during follow-up for use of antimalarial drugs outside of the study, development of concomitant febrile illnesses that interfered with the assessment of study outcomes, occurrence of any serious adverse event requiring a change in treatment, withdrawal of informed consent, and loss of follow-up (unable to be located within 24 hours on Days 1-3 or within 48 hours on Days 4-28).

At each follow-up visit study clinicians assessed patients for adverse events and graded them according to scales developed by the WHO and the National Institutes of Health. An adverse event was defined as any untoward medical occurrence, following International Conference on Harmonization guidelines. A serious adverse event was defined as an experience that results in death, life-threatening experience, inpatient hospitalization, persistent or significant incapacity, or medical or surgical intervention to prevent serious outcomes.

Laboratory procedures. Thick and thin blood smears were stained with $2 \%$ Giemsa. Parasite densities were calculated from thick blood smears by counting the number of asexual parasites per 200 leukocytes (or per 500, if the count was $<10$ parasites/200 leukocytes), assuming a leukocyte count of $8,000 / \mu \mathrm{L}$. A thick blood smear was considered negative when the examination of 100 high-power fields did not reveal parasites. Gametocytes were recorded as present or absent. Thin blood smears were evaluated to determine parasite species. Hemoglobin was measured from finger prick blood samples using a portable spectrophotometer, HemoCue (HemoCue, Angelolm, Sweden).

Whenever blood was collected, samples were placed onto filter paper in approximately $25 \mu \mathrm{L}$ aliquots per spot ( 4 spots per sample). The samples were labeled, air-dried, and stored in small, sealed sample bags at ambient temperature. Parasite DNA was subsequently extracted from the filter paper using chelex. ${ }^{11}$ To distinguish recrudescent and new infections, for all patients failing therapy after Day 6, parasites collected at baseline (Day 0) and at the time of failure were compared by genotyping, as previously described. ${ }^{12}$ Briefly, we amplified the block 3 region of the merozoite surface protein 2 gene by nested PCR, and characterized this gene on the basis of sequence and size polymorphisms identified by restriction endonuclease digestion and gel electrophoresis. Genotyping patterns on the day of failure were compared with those at treatment initiation, using GelCompar II software (Applied Maths, Austin, TX). We defined an outcome as recrudescence if treatment failure occurred prior to Day 7 or when at the time of repeat therapy a sample contained only alleles that were present on Day 0 . We defined a new infection when at the time of repeat therapy a sample contained any new alleles.

Statistical analysis. Sample size calculations were based on the estimated efficacies of the study regimens. We tested the 
hypothesis that, compared with treatment with either AQ or $\mathrm{SP}$, treatment with $\mathrm{AQ}+\mathrm{SP}$ would decrease the risk of any treatment failure (unadjusted by genotyping) at 28 days from 12 to $5 \%$. Calculations were made using an $\alpha=0.05$ and a statistical power of $80 \%$ based on a two-sided test. Allowance was made for a $10 \%$ loss of follow-up. Based on these assumptions, the sample size for the treatment groups was 921 patients (307 per treatment arm).

Data were entered and verified using EpiInfo 6.04 (Centers for Disease Control and Prevention, Atlanta, GA) and analyzed using SPSS version 12.0 (SPSS, Chicago, IL) and Stata version 8.0 (Stata, College Station, TX). Data from all three sites were combined, and efficacy data were evaluated using a per-protocol analysis, including only patients with treatment outcomes. Parasite densities were normalized using logarithmic transformation. Categorical variables were compared using $\chi^{2}$ or Fisher's exact test and continuous variables compared using an independent samples $t$ test. Risks of clinical and parasitological treatment failure after adjustment by genotyping were estimated using Kaplan-Meier survival analysis techniques. With survival analysis, data were censored for the competing risk (new infections censored when estimating risks of recrudescence and vice versa). A $P$ value (two-tailed) of less than 0.05 was considered statistically significant.

\section{RESULTS}

Enrollment and baseline characteristics. Of 1,232 patients referred for assessment, 284 were excluded during screening and 4 after randomization (Figure 1). Of the 944 patients enrolled, 829 (88\%) were assigned efficacy outcomes and were included in the per-protocol analysis. Exclusion after enrollment occurred in $12.2 \%$ of patients, in $8.6 \%$ due to withdrawal of informed consent, in $2.2 \%$ due to use of nonstudy antimalarial medications, and in $1.4 \%$ due to loss of follow-up (Figure 1). The difference in the proportion that was enrolled but did not complete the study was not significantly different between treatment groups $(P=0.82)$. The baseline characteristics of those who completed the study are summarized in Table 1 . The ages, genders, mean temperatures upon presentation, proportions with prior chloroquine use, and parasitological and hematological criteria were not significantly different for the three treatment arms. About half $(53 \%)$ of subjects were under 5 years of age.

Primary treatment efficacy. For all treatments, ETFs were uncommon (Table 2). Considering both clinical and parasitological outcomes without adjustment by genotyping, the risks of failure for the three regimens were $17.9 \%$ for AQ, $9.1 \%$ for SP, and $4.2 \%$ for AQ + SP $(P<0.02$ for all pairwise comparisons; Tables 2 and 3). Considering only clinical failures, relative efficacies were similar to those including all failures (risks of clinical failure $13.2 \%$ for AQ, 6.5\% for SP, and $2.1 \%$ for AQ $+\mathrm{SP} ; P<0.02$ for all pairwise comparisons; Table 2).

To discriminate recrudescences from new infections, infecting isolates were analyzed based on polymorphisms in the merozoite surface protein 2 gene. Genotyping of 70 samples from patients with LCF or LPF treatment outcomes identified 182 distinct alleles (87 FC27 family, 95 IC3D7 family; mean complexity of infection 2.6). Using simple statistical techniques, the probability that two independent alleles were classified as the same was calculated to be $4.9 \%$. Thus, the diver- sity of msp-2 alleles in the study population was high, and the probability of misclassifying a new infection as a recrudescence was low.

Stratifying recrudescences and new infections was informative. Considering only recrudescence, the risk of failure was lower in the AQ + SP (2.1\%) treatment group compared with the SP $(6.1 \%, P=0.02)$ and AQ $(8.1 \%, P=0.001)$ groups (Table 3). The risk of new infection was lower in the AQ + SP $(2.1 \%)$ and SP $(2.4 \%)$ treatment groups compared with the AQ group ( $9.1 \% ; P<0.001$ for both comparisons; Table 3 ). The benefit of SP over AQ was thus primarily due to the prevention of new infections, but not recrudescences. Indeed, it appeared that the chemoprophylactic effect was due solely to SP, as AQ + SP offered no benefit over SP monotherapy for the prevention of new infections. The combination therapy offered benefit over AQ in terms of prevention of new infection and over both monotherapies for prevention of recrudescence.

Secondary outcomes and safety. The treatment regimens varied in terms of secondary outcomes (Table 4). The proportion of patients with persistent parasitemia on Day 3 was greatest for SP and lowest for AQ + SP. The combination regimen also offered the most rapid resolution of fever, although differences between AQ and AQ + SP were minimal, with both showing significantly more rapid fever resolution on Days 1, 2, and 3 compared with SP. Gametocytes were seen during follow-up most commonly in SP-treated patients. Hemoglobin recovery was greatest with $\mathrm{AQ}+\mathrm{SP}$, although differences between treatments did not reach statistical significance.

The proportions of patients with any adverse event were similar across the three treatment groups, ranging from $37 \%$ to $40 \%$ (Table 4$)$. The most common adverse events were cough $(11 \%)$, corzya $(7 \%)$, pruritis $(7 \%)$, anorexia $(7 \%)$, vomiting (4\%), abdominal pain (4\%), and weakness $(3 \%)$. The incidence of individual adverse events was similar across the three treatment groups, with the exception of pruritis, which was more common in the treatment arms containing AQ $(9 \%)$ compared with the SP arm $(3 \%, P=0.006)$. No serious adverse events were reported in any of the treatment arms.

\section{DISCUSSION}

The antimalarial efficacy of CQ in Burkina Faso is no longer acceptable, and, as is the case in nearly all of Africa, new regimens need to be identified. ${ }^{9,13}$ ACTs are potential options, but due to their high cost and limited availability, it is important that other options are also considered. Among other options are AQ and SP, the two most common replacements for CQ in Africa, which are both inexpensive and readily available. In other parts of Africa resistance to both of these drugs has been increasing, ${ }^{14-17}$ but the combination of AQ + SP has shown surprisingly good efficacy, even in regions with fairly high levels of resistance to each of the drugs. ${ }^{15,18-23}$ Resistance to both AQ and SP seems to be at a lower level in Burkina Faso than in most of Africa, although studies are limited. ${ }^{13,24-26}$ To explore options to replace CQ for the treatment of uncomplicated malaria in Burkina Faso, we performed a randomized controlled trial comparing the efficacies of AQ, SP, and the combination of these drugs. Our 


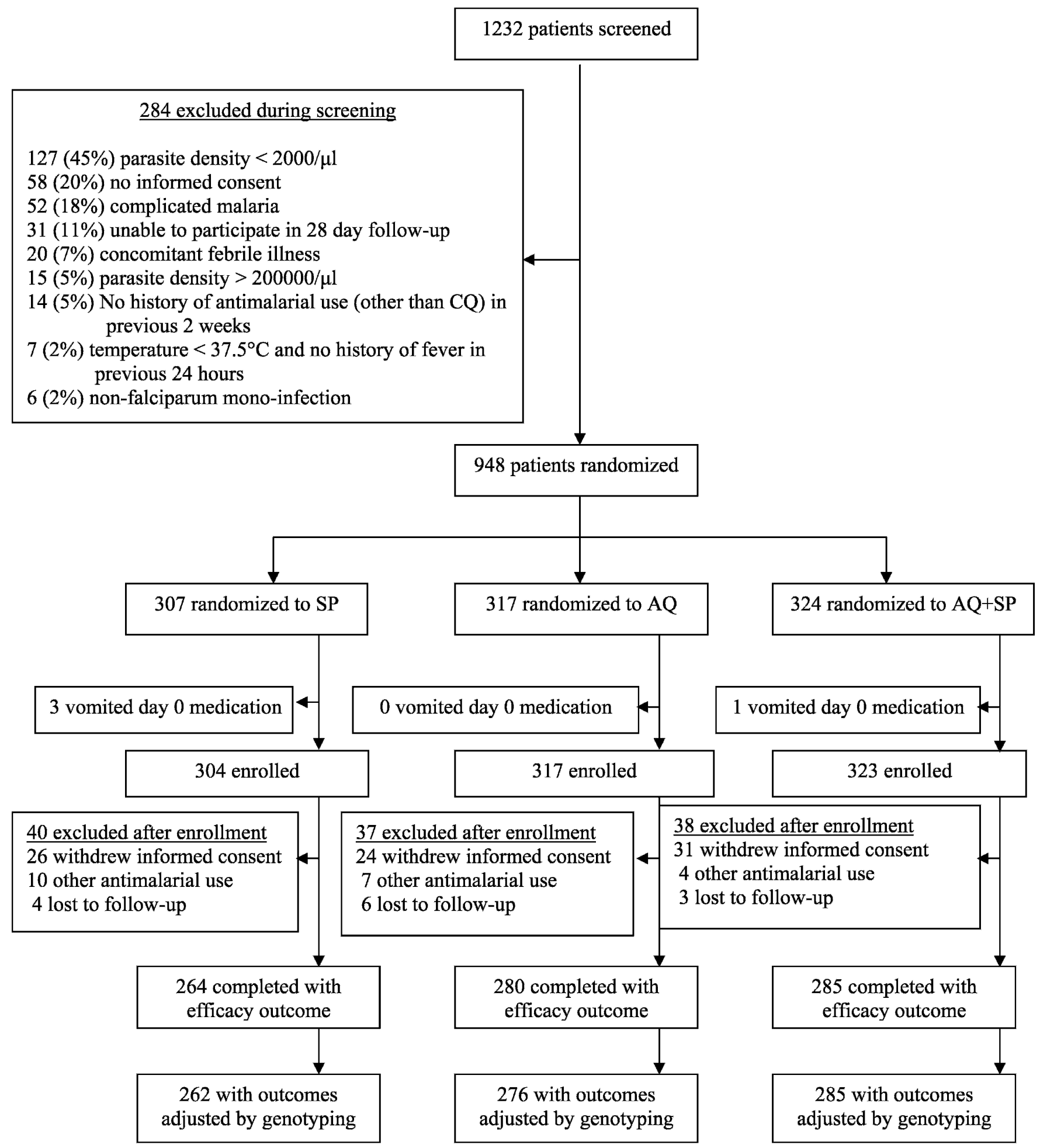

FIGURE 1. Trial profile. $\mathrm{SP}=$ sulfadoxine-pyrimethamine. $\mathrm{AQ}=$ amodiaquine. $\mathrm{AQ}+\mathrm{SP}=$ amodiaquine plus sulfadoxine-pyrimethamine.

study benefited from a large sample size, 28-day follow-up, and the inclusion of genotyping in outcomes analyses. We found that each drug had fairly good efficacy, and that AQ + SP was highly efficacious.

Our most important result was that 28-day outcomes after treatment with AQ + SP were excellent. Failures after AQ + SP therapy were uncommon $(4.2 \%)$, with very few clinical failures $(2.1 \%)$ over 4 weeks of follow-up. Additional analysis highlighted the contributions of each component of the combination. Failures after treatment with SP monotherapy were uncommon $(9.1 \%)$, suggesting that resistance to SP is much less prevalent in Burkina Faso than in some other parts of Africa. Genotyping showed that SP treatment failures were mostly due to recrudescent infections. Failures after treat- 
TABLE 1

Baseline charcteristics of patients with efficacy outcomes

\begin{tabular}{|c|c|c|c|}
\hline Baseline characteristic & $\begin{array}{c}\mathrm{SP} \\
(N=264)\end{array}$ & $\begin{array}{c}\mathrm{AQ} \\
(N=280)\end{array}$ & $\begin{array}{l}\mathrm{AQ}+\mathrm{SP} \\
(N=285)\end{array}$ \\
\hline \multicolumn{4}{|l|}{ Study site } \\
\hline Colsama & 61 & 70 & 74 \\
\hline Sarfalao & 111 & 115 & 122 \\
\hline Ouezzin-ville & 92 & 95 & 89 \\
\hline Gender (\% female) & $48 \%$ & $50 \%$ & $49 \%$ \\
\hline $\begin{array}{l}\text { Median age in years } \\
\text { (range) }\end{array}$ & $4.6(0.5-52)$ & $4.0(0.5-40)$ & $4.0(0.5-44)$ \\
\hline $\begin{array}{l}\text { Age less than } 5 \text { years, no. } \\
(\%)\end{array}$ & $133(50 \%)$ & $159(57 \%)$ & $152(53 \%)$ \\
\hline $\begin{array}{l}\text { CQ use in previous } \\
2 \text { weeks, no. }(\%)^{*}\end{array}$ & $25(10 \%)$ & $20(7 \%)$ & $26(10 \%)$ \\
\hline $\begin{array}{l}\text { Mean temperature }\left({ }^{\circ} \mathrm{C}\right) \\
(\mathrm{SD})\end{array}$ & $38.3(0.9)$ & $38.4(0.9)$ & $38.5(0.9)$ \\
\hline $\begin{array}{l}\text { Geometric mean parasite } \\
\text { density } / \mu \mathrm{L}\end{array}$ & 20885 & 20134 & 21672 \\
\hline $\begin{array}{l}\text { Mean hemoglobin }(\mathrm{g} / \mathrm{dL}) \\
\text { (SD) }\end{array}$ & $10.0(2.2)$ & $10.0(2.2)$ & $9.9(2.2)$ \\
\hline $\begin{array}{l}\text { Gametocytes present, no. } \\
(\%)\end{array}$ & $1(0.4 \%)$ & $3(1.1 \%)$ & $2(0.7 \%)$ \\
\hline
\end{tabular}

aquine; $\mathrm{CQ}$, chloroquine

* Only includes patients with available data.

ment with AQ were more common (17.9\%), and these recurrent infections were about equally split between recrudescences and new infections. SP provided less rapid resolution of fever, compared with AQ. Thus, consistent with the known pharmacokinetics of these compounds, ${ }^{27-29} \mathrm{AQ}$ was more rapid acting, but $\mathrm{SP}$, which has a prolonged half-life, offered a late benefit, with some protection against new infections extending for weeks after treatment. The more rapid action of $\mathrm{AQ}$ is likely due both to its inherent biologic activity and its antipyretic effects. The long-term prophylactic effect of SP is likely due to its extended half-life. With the combination of these two drugs, AQ + SP offered a highly efficacious therapy.

A concern with $\mathrm{AQ}+\mathrm{SP}$ is safety, as both components of this combination have been seen to rarely cause serious toxicity. Chemoprophylaxis with AQ has been associated with bone marrow and hepatic toxicity, with a death rate estimated at 1 in $15,650 .{ }^{30}$ When used for chemoprophylaxis, SP has caused serious skin toxicity, with an estimated fatality rate of 1 in $11,100 .{ }^{30}$ For both drugs, short-term treatment appears to be safer than chronic chemoprophylactic dosing. ${ }^{31}$ Our study included full evaluations after more than 500 treatments with

TABLE 2

Treatment outcomes at Day 28

\begin{tabular}{|c|c|c|c|}
\hline Outcome & $(N \stackrel{\mathrm{SP}}{=} 264)$ & $(N \stackrel{S P}{=} 280)$ & $\begin{array}{l}\mathrm{AQ}+\mathrm{SP} \\
(N=285)\end{array}$ \\
\hline Early treatment failure & $5(1.9 \%)$ & $2(0.7 \%)$ & $2(0.7 \%)$ \\
\hline Late clinical failure & $12(4.6 \%)$ & $35(12.5 \%)$ & $4(1.4 \%)$ \\
\hline Recrudescence & $7(2.7 \%)$ & $17(6.1 \%)$ & $2(0.7 \%)$ \\
\hline New infection & $4(1.5 \%)$ & $14(5.0 \%)$ & $2(0.7 \%)$ \\
\hline No genotyping results & $1(0.4 \%)$ & $4(1.4 \%)$ & 0 \\
\hline Late parasitological failure & $7(2.7 \%)$ & $13(4.6 \%)$ & $6(2.1 \%)$ \\
\hline Recrudescence & $4(1.4 \%)$ & $3(1.1 \%)$ & $2(0.7 \%)$ \\
\hline New infection & $2(0.8 \%)$ & $10(3.6 \%)$ & $4(1.4 \%)$ \\
\hline No genotyping results & $1(0.4 \%)$ & 0 & 0 \\
\hline $\begin{array}{l}\text { Adequate clinical and } \\
\text { parasitological response }\end{array}$ & $240(90.9 \%)$ & $230(82.1 \%)$ & $273(95.8 \%)$ \\
\hline
\end{tabular}

TABLE 3

Comparisons of treatment outcomes

\begin{tabular}{|c|c|c|c|c|}
\hline $\begin{array}{l}\text { Treatment group } \\
\text { comparisons }\end{array}$ & $\begin{array}{l}\text { Risk of outcome in } \\
\text { comparison groups }\end{array}$ & $\begin{array}{c}\text { Risk } \\
\text { difference }\end{array}$ & $95 \% \mathrm{CI}$ & $P$ value \\
\hline \multicolumn{5}{|c|}{ Outcome $=$ any treatment failure } \\
\hline AQ vs. SP & $17.9 \%$ vs. $9.1 \%$ & $8.8 \%$ & $3.1-14.4 \%$ & 0.004 \\
\hline $\mathrm{SP}$ vs. $\mathrm{AQ}+\mathrm{SP}$ & $9.1 \%$ vs. $4.2 \%$ & $4.9 \%$ & $0.7-9.1 \%$ & 0.02 \\
\hline $\mathrm{AQ}$ vs. $\mathrm{AQ}+\mathrm{SP}$ & $17.9 \%$ vs. $4.2 \%$ & $13.6 \%$ & $8.6-18.7 \%$ & $<0.0001$ \\
\hline \multicolumn{5}{|c|}{ Outcome $=$ recrudescence } \\
\hline AQ vs. SP & $8.1 \%$ vs. $6.1 \%$ & $2.0 \%$ & $-2.4-6.4 \%$ & 0.37 \\
\hline $\mathrm{SP}$ vs. $\mathrm{AQ}+\mathrm{SP}$ & $6.1 \%$ vs. $2.1 \%$ & $4.0 \%$ & $0.7-7.4 \%$ & 0.02 \\
\hline$A Q$ vs. $A Q+S P$ & $8.1 \%$ vs. $2.1 \%$ & $6.0 \%$ & $2.4-9.7 \%$ & 0.001 \\
\hline \multicolumn{5}{|c|}{ Outcome $=$ new infection } \\
\hline AQ vs. SP & $9.1 \%$ vs. $2.4 \%$ & $6.7 \%$ & $2.8-10.7 \%$ & 0.0008 \\
\hline $\mathrm{SP}$ vs. $\mathrm{AQ}+\mathrm{SP}$ & $2.4 \%$ vs. $2.1 \%$ & $0.2 \%$ & $-2.2-2.8 \%$ & 0.85 \\
\hline$A Q$ vs. $A Q+S P$ & $9.1 \%$ vs. $2.1 \%$ & $7.0 \%$ & $3.1-10.8 \%$ & 0.0004 \\
\hline
\end{tabular}

each drug and 285 treatments with the combination. Adverse events were common, but were consistent with the natural history of malaria, except for an increased incidence of pruritis in AQ-treated individuals. No serious adverse events were identified. These data and additional safety information from elsewhere in Africa ${ }^{15,18,19}$ offer reassurance that serious toxicity after treatment of malaria with $\mathrm{AQ}+\mathrm{SP}$ will be uncommon. However, in this study we did not rigorously assess the impacts of study regimens on hematological or biochemical parameters, and additional assessment of the safety of AQ + SP seems warranted.

The continued strong efficacy of SP and fairly good efficacy of AQ in Burkina Faso might suggest that there is still a place for these monotherapies in the standard treatment of uncomplicated malaria. However, experience from other areas suggests that the monotherapies will select for increasing levels of resistance, and that combination therapy is now appropriate. Combining drugs that retain good efficacy should improve over the efficacy of either compound, as seen in our study with $\mathrm{AQ}+\mathrm{SP}$, and it should hinder the selection of drug-resistant parasites. $^{3}$ Indeed, AQ + SP may be quite robust, as the pharmacokinetics of the three compounds included in this regimen are fairly well matched. ${ }^{27-29}$ More convincing than theoretical arguments are data from multiple

TABLE 4

Comparison of secondary treatment outcomes

\begin{tabular}{|c|c|c|c|}
\hline Secondary outcomes & $(N \stackrel{\mathrm{SP}}{=} 264)$ & $\begin{array}{c}\mathrm{AQ} \\
(N=280)\end{array}$ & $\begin{array}{l}\mathrm{SP}+\mathrm{AQ} \\
(N=285)\end{array}$ \\
\hline $\begin{array}{l}\text { Proportion with parasitemia } \\
\text { on Day } 3 * \dagger\end{array}$ & $10 \%$ & $7 \%$ & $2 \%$ \\
\hline $\begin{array}{l}\text { Proportion with temperature } \\
\quad \geq 37.5^{\circ} \mathrm{C}\end{array}$ & & & \\
\hline Day 0 & $83 \%$ & $88 \%$ & $88 \%$ \\
\hline Day $1 * \ddagger$ & $30 \%$ & $14 \%$ & $13 \%$ \\
\hline Day $2 * \ddagger$ & $20 \%$ & $4 \%$ & $3 \%$ \\
\hline Day $3 * \div$ & $6 \%$ & $3 \%$ & $2 \%$ \\
\hline $\begin{array}{l}\text { Proportion with gametocytes } \\
\text { during follow-up* } *\end{array}$ & $19 \%$ & $8 \%$ & $8 \%$ \\
\hline $\begin{array}{l}\text { Increase in hemoglobin } \\
\mathrm{g} / \mathrm{dL}(\mathrm{SD})\end{array}$ & $0.99(1.78)$ & $0.84(1.69)$ & $1.08(1.81)$ \\
\hline $\begin{array}{l}\text { Proportion of patients with } \\
\text { any adverse event }\end{array}$ & $38 \%$ & $40 \%$ & $37 \%$ \\
\hline
\end{tabular}


countries in Africa, showing strong efficacy of AQ + SP even in settings where resistance to the component drugs is much greater than that in Burkina Faso. ${ }^{15,18-23}$

Many authorities now advocate ACT for the routine treatment of malaria throughout Africa, but our data suggest that $\mathrm{AQ}+\mathrm{SP}$ offers outstanding efficacy in Burkina Faso at a cost much less than that of ACT regimens. What, then, is the appropriate national malaria treatment regimen? If availability improves, and especially if costs decrease, ACT regimens are still a promising option. Although data available to date from Africa with CQ + artesunate $^{9}$ and $\mathrm{SP}+$ artesunate $^{32-35}$ are unsatisfying, it is expected that regimens with improved artemisinin partner drugs, for example AQ + artesunate, ${ }^{23,26,36}$ lumefantrine + artemether, ${ }^{36}$ and piperaquine + dihydroartemisinin will show improved efficacy in Africa, as has been the case in Asia. ${ }^{37-41}$ Artemisinins also show excellent ability to limit gametocytes, potentially offering an added malaria control benefit. However, ACT will only be effective if it is implemented, and a worry is that, due to cost and availability constraints, limited supplies of ACT will lead to continued heavy use of monotherapies to treat malaria in Burkina Faso. Rather, we suggest that rapid implementation of an effective combination therapy is the best means of both treating malaria and halting the progression of drug resistance. Our study has shown that AQ + SP offers outstanding efficacy and suggests that this inexpensive regimen is worthy of urgent consideration for the treatment of malaria in Burkina Faso.

\section{Received April 20, 2005. Accepted for publication June 6, 2005.}

Acknowledgments: The authors thank the clinical study teams in the dispensaries of Colsama (Minata Yampa, Christine Ouaro Sylvain Zoundi), Sarlafao (Georgette Dabire, Gneme Moumouni), and Ouezzin-Ville (Yolande Sanou, Korotoumou Sontie, Aissiata Boly) and the laboratory technicians (Patrice Hien, Adama Sankara, Daouda Traore, San Coulibaly, Mahamoudou Minoungou). We also thank Assobga Franck Godefroy, Harouna Zigani, and Halidou Tinto for assistance with data entry and Heidi Hopkins for assistance in protocol preparation.

Financial support: This work was supported by grant D43 TW01506 from the Fogarty International Center of the National Institutes of Health.

Authors' addresses: Issaka Zongo, Noel Rouamba, Moise Lankoande, and Jean-Bosco Ouedraogo, Institut de Recherche en Sciences de la Santé, Bobo-Dioulasso, Burkina Faso. Grant Dorsey, Christian Dokomajilar, and Philip J. Rosenthal, Box 0811, University of California, San Francisco, CA 94143.

Reprint requests: Philip J. Rosenthal, Box 0811, University of California, San Francisco, CA 94143, Telephone: 1-415-206-8845, Fax: 1-415-648-8425, E-mail: rosnthl@itsa.ucsf.edu.

\section{REFERENCES}

1. Guerin PJ, Olliaro P, Nosten F, Druilhe P, Laxminarayan R, Binka F, Kilama WL, Ford N, White NJ, 2002. Malaria: current status of control, diagnosis, treatment, and a proposed agenda for research and development. Lancet Infect Dis 2: 564-573.

2. White NJ, 2004. Antimalarial drug resistance. J Clin Invest 113: 1084-1092.

3. Kremsner PG, Krishna S, 2004. Antimalarial combinations. Lancet 364: 285-294.

4. Nosten F, van Vugt M, Price R, Luxemburger C, Thway KL, Brockman A, McGready R, ter Kuile F, Looareesuwan S, White NJ, 2000. Effects of artesunate-mefloquine combination on incidence of Plasmodium falciparum malaria and meflo- quine resistance in western Thailand: a prospective study. Lancet 356: 297-302.

5. Attaran A, 2004. Rescuing malaria treatment, or not? Lancet 364: 1922-1923.

6. Laxminarayan R, 2004. Act now or later? Economics of malaria resistance. Am J Trop Med Hyg 71: 187-195.

7. McGready R, Cho T, Keo NK, Thwai KL, Villegas L, Looareesuwan S, White NJ, Nosten F, 2001. Artemisinin antimalarials in pregnancy: a prospective treatment study of 539 episodes of multidrug-resistant Plasmodium falciparum. Clin Infect Dis 33: 2009-2016.

8. Cyranoski D, 2004. Campaign to fight malaria hit by surge in demand for medicine. Nature 432: 259.

9. Sirima SB, Tiono AB, Konate A, Diarra A, Castelli F, Pinoges L, Mugittu K, Taylor WR, Olliaro PL, 2003. Efficacy of artesunate plus chloroquine for the treatment of uncomplicated malaria in children in Burkina Faso: a double-blind, randomized, controlled trial. Trans $R$ Soc Trop Med Hyg 97: 345-349.

10. WHO, 2003. Assessment and monitoring of antimalarial drug efficacy for the treatment of uncomplicated falciparum malaria. Geneva: World Health Organization, 68.

11. Plowe CV, Djimde A, Bouare M, Doumbo O, Wellems TE, 1995. Pyrimethamine and proguanil resistance-conferring mutations in Plasmodium falciparum dihydrofolate reductase: polymerase chain reaction methods for surveillance in Africa. Am J Trop Med Hyg 52: 565-568.

12. Cattamanchi A, Kyabayinze D, Hubbard A, Rosenthal PJ, Dorsey G, 2003. Distinguishing recrudescence from reinfection in a longitudinal antimalarial drug efficacy study: comparison of results based on genotyping of $m s p-1, m s p-2$, and glurp. Am J Trop Med Hyg 68: 133-139.

13. Tinto H, Zoungrana EB, Coulibaly SO, Ouedraogo JB, Traore M, Guiguemde TR, Van Marck E, D'Alessandro U, 2002. Chloroquine and sulphadoxine-pyrimethamine efficacy for uncomplicated malaria treatment and haematological recovery in children in Bobo-Dioulasso, Burkina Faso during a 3-year period 1998-2000. Trop Med Int Health 7: 925-930.

14. Mutabingwa TK, Maxwell CA, Sia IG, Msuya FH, Mkongewa S, Vannithone S, Curtis J, Curtis CF, 2001. A trial of proguanildapsone in comparison with sulfadoxine-pyrimethamine for the clearance of Plasmodium falciparum infections in Tanzania. Trans R Soc Trop Med Hyg 95: 433-438.

15. Gasasira AF, Dorsey G, Nzarubara B, Staedke SG, Nassali A, Rosenthal PJ, Kamya MR, 2003. Comparative efficacy of aminoquinoline-antifolate combinations for the treatment of uncomplicated falciparum malaria in Kampala, Uganda. Am J Trop Med Hyg 68: 127-132.

16. Vreugdenhil CJ, Scheper FY, Hoogstraatte SR, Smolders M, Gikunda S, Cobelens FG, Kager PA, 2004. Comparison of the parasitologic efficacy of amodiaquine and sulfadoxinepyrimethamine in the treatment of Plasmodium falciparum malaria in the Bungoma District of western Kenya. Am J Trop Med Hyg 71: 537-541.

17. Stivanello E, Cavailler P, Cassano F, Omar SA, Kariuki D, Mwangi J, Piola P, Guthmann JP, 2004. Efficacy of chloroquine, sulphadoxine-pyrimethamine and amodiaquine for treatment of uncomplicated Plasmodium falciparum malaria in Kajo Keji county, Sudan. Trop Med Int Health 9: 975-980.

18. Staedke SG, Kamya MR, Dorsey G, Gasasira A, Ndeezi G, Charlebois ED, Rosenthal PJ, 2001. Amodiaquine, sulfadoxine/ pyrimethamine, and combination therapy for treatment of uncomplicated falciparum malaria in Kampala, Uganda: a randomised trial. Lancet 358: 368-374.

19. Schellenberg D, Kahigwa E, Drakeley C, Malende A, Wigayi J, Msokame C, Aponte JJ, Tanner M, Mshinda H, Menendez C, Alonso PL, 2002. The safety and efficacy of sulfadoxinepyrimethamine, amodiaquine, and their combination in the treatment of uncomplicated Plasmodium falciparum malaria. Am J Trop Med Hyg 67: 17-23.

20. Rwagacondo CE, Niyitegeka F, Sarushi J, Karema C, Mugisha V, Dujardin JC, Van Overmeir C, van den Ende J, D'Alessandro U, 2003. Efficacy of amodiaquine alone and combined with sulfadoxine-pyrimethamine and of sulfadoxine pyrimethamine combined with artesunate. Am J Trop Med Hyg 68: 743-747.

21. Sowunmi A, 2002. A randomized comparison of chloroquine, 
amodiaquine and their combination with pyrimethaminesulfadoxine in the treatment of acute, uncomplicated, Plasmodium falciparum malaria in children. Ann Trop Med Parasitol 96: 227-238.

22. Dorsey G, Vlahos J, Kamya MR, Staedke SG, Rosenthal PJ, 2003. Prevention of increasing rates of treatment failure by combining sulfadoxine-pyrimethamine with artesunate or amodiaquine for the sequential treatment of malaria. $J$ Infect Dis 188: 1231-1238.

23. Staedke SG, Mpimbaza A, Kamya MR, Nzarubara BK, Dorsey G, Rosenthal PJ, 2004. Combination treatments for uncomplicated falciparum malaria in Kampala, Uganda: randomised clinical trial. Lancet 364: 1950-1957.

24. Del Nero L, Lamizana L, Pietra V, Nebie I, 1994. Sensitivity to antimalarial drugs by Plasmodium falciparum in Goundry, Oubritenga province, Burkina Faso. Parassitologia 36: 287-293.

25. Muller O, Traore C, Kouyate B, 2004. Efficacy of pyrimethamine-sulfadoxine in young children with uncomplicated falciparum malaria in rural Burkina Faso. Malar J 3: 10.

26. Barennes H, Nagot N, Valea I, Koussoube-Balima T, Ouedraogo A, Sanou T, Ye S, 2004. A randomized trial of amodiaquine and artesunate alone and in combination for the treatment of uncomplicated falciparum malaria in children from Burkina Faso. Trop Med Int Health 9: 438-444.

27. Krishna S, White NJ, 1996. Pharmacokinetics of quinine, chloroquine and amodiaquine. Clinical implications. Clin Pharmacokinet 30: 263-299.

28. Winstanley PA, Ward SA, Snow RW, 2002. Clinical status and implications of antimalarial drug resistance. Microbes Infection 4: $157-164$.

29. Bustos DG, Lazaro JE, Gay F, Pottier A, Laracas CJ, Traore B, Diquet B, 2002. Pharmacokinetics of sequential and simultaneous treatment with the combination chloroquine and sulfadoxine-pyrimethamine in acute uncomplicated Plasmodium falciparum malaria in the Philippines. Trop Med Int Health 7: 584-591.

30. Phillips-Howard PA, West LJ, 1990. Serious adverse drug reactions to pyrimethamine-sulphadoxine, pyrimethaminedapsone and to amodiaquine in Britain. $J$ R Soc Med 83: 82-85.

31. Olliaro P, Nevill C, LeBras J, Ringwald P, Mussano P, Garner P, Brasseur P, 1996. Systematic review of amodiaquine treatment in uncomplicated malaria. Lancet 348: 1196-1201.

32. Dorsey G, Njama D, Kamya MR, Cattamanchi A, Kyabayinze D, Staedke SG, Gasasira A, Rosenthal PJ, 2002. Sulfadoxine/ pyrimethamine alone or with amodiaquine or artesunate for treatment of uncomplicated malaria: a longitudinal randomised trial. Lancet 360: 2031-2038.

33. Obonyo CO, Ochieng F, Taylor WR, Ochola SA, Mugitu K, Olliaro P, ter Kuile F, Oloo AJ, 2003. Artesunate plus sulfadoxine-pyrimethamine for uncomplicated malaria in Kenyan children: a randomized, double-blind, placebo-controlled trial. Trans $R$ Soc Trop Med Hyg 97: 585-591.

34. Priotto G, Kabakyenga J, Pinoges L, Ruiz A, Eriksson T, Coussement F, Ngambe T, Taylor WR, Perea W, Guthmann JP, Olliaro P, Legros D, 2003. Artesunate and sulfadoxinepyrimethamine combinations for the treatment of uncomplicated Plasmodium falciparum malaria in Uganda: a randomized, double-blind, placebo-controlled trial. Trans $R$ Soc Trop Med Hyg 97: 325-330.

35. Depoortere E, Guthmann JP, Presse J, Sipilanyambe N, Nkandu E, Balkan S, de Pecoulas PE, Legros D, 2005. Efficacy and effectiveness of the combination of sulfadoxine/pyrimethamine and a 3-day course of artesunate for the treatment of uncomplicated falciparum malaria in a refugee settlement in Zambia. Trop Med Int Health 10: 139-145.

36. Ndayiragije A, Niyungeko D, Karenzo J, Niyungeko E, Barutwanayo M, Ciza A, Bosman A, Moyou-Somo R, Nahimana A, Nyarushatsi JP, Barihuta T, Mizero L, Ndaruhutse J, Delacollette C, Ringwald P, Kamana J, 2004. Efficacy of therapeutic combinations with artemisinin derivatives in the treatment of non complicated malaria in Burundi. Trop Med Int Health 9: 673-679.

37. Denis MB, Davis TM, Hewitt S, Incardona S, Nimol K, Fandeur T, Poravuth Y, Lim C, Socheat D, 2002. Efficacy and safety of dihydroartemisinin-piperaquine (Artekin) in Cambodian children and adults with uncomplicated falciparum malaria. Clin Infect Dis 35: 1469-1476.

38. Tran TH, Dolecek C, Pham PM, Nguyen TD, Nguyen TT, Le HT, Dong TH, Tran TT, Stepniewska K, White NJ, Farrar J, 2004. Dihydroartemisinin-piperaquine against multidrug-resistant Plasmodium falciparum malaria in Vietnam: randomised clinical trial. Lancet 363: 18-22.

39. Ashley EA, Krudsood S, Phaiphun L, Srivilairit S, McGready R, Leowattana W, Hutagalung R, Wilairatana P, Brockman A, Looareesuwan S, Nosten F, White NJ, 2004. Randomized, controlled dose-optimization studies of dihydroartemisininpiperaquine for the treatment of uncomplicated multidrugresistant falciparum malaria in Thailand. J Infect Dis 190: 1773-1782.

40. Vugt MV, Wilairatana P, Gemperli B, Gathmann I, Phaipun L, Brockman A, Luxemburger C, White NJ, Nosten F, Looareesuwan S, 1999. Efficacy of six doses of artemetherlumefantrine (benflumetol) in multidrug-resistant Plasmodium falciparum malaria. Am J Trop Med Hyg 60: 936-942.

41. Van Vugt M, Angus BJ, Price RN, Mann C, Simpson JA, Poletto C, Htoo SE, Looareesuwan S, White NJ, Nosten F, 2000. A case-control auditory evaluation of patients treated with artemisinin derivatives for multidrug-resistant Plasmodium falciparum malaria. Am J Trop Med Hyg 62: 65-69. 